\title{
뇌졸중 노인의 역할수행이 활동역량과 작업참여에 미치는 영향
}

\author{
배성환, $\mathrm{OT}, \mathrm{MS}^{1}$, 백지영, $\mathrm{OT}, \mathrm{PhD}^{* 2}$ \\ ${ }^{1}$ 동신대학교 작업치료학과, ${ }^{*}$ 동신대학교 작업치료학과
}

An Effect of Role Performance of the Elderly with Stroke on Activity Competency and Occupational Participation

Seong-Hwan Bae, OT, MS ${ }^{1}$, Ji-Young Baek, OT, $\mathrm{PhD}^{* 2}$

'Dept. of Occupational Therapy, Dongshin University, Republic of Korea

${ }^{* 2}$ Dept. of Occupational Therapy, Dongshin University, Republic of Korea

Purpose The purpose of this research is to identify the effect of stroke elder's role performance upon his activity competency and working participation, and to provide the basis of intervention to internalize the normal role of stroke elder. Methods This research was progressed to 35 stroke elders who entered and visited to $\mathrm{P}$ hospital located at $\mathrm{S}$ city. The assessment tools were role checklist(RC V3) to identify the role performance, occupational questionnaire( $\mathrm{OQ})$ to identify the activity competency, and Model of Human Occupation Screening Tool(MOHOST) to identify the occupational participation. Results The role performance of stroke elder showed the interrelation between activity competence and occupational participation $(\mathrm{p}<.05)$. Also, the role performance of stroke elder had effect upon the activity competence $(\mathrm{p}<.05)$ and occupational participation $(\mathrm{p}<.01)$. Conclusion I discovered the fact that the role performance of stroke elder showed the relevance in the activity competence and occupational participation and that the role performance of stroke elder had the effect upon the activity competence and occupational participation. Therefore, I think if we put our interest in promoting and intervening the role performance for stroke elder's role internalization, it would be possible to improve the activity competence and occupational participation of stroke elder.

Key words Role performance, Activity competence, Occupational participation, Stroke, The elderly

Corresponding author Ji-Young Baek (otwhite@hanmail.net)

Received date 30 September 2020

Revised date 10 October 2020

Accept date 13 October 2020

\section{I. 서 론}

의료기술의 발달로 인한 평균수명의 연장으로 전 세계적으로 노인인구가 증가하는 추세를 보이는 가운데, ${ }^{1)}$ 우리나라의 2018 년 노인인구는 전체 인구의 $14.3 \%, 2020$ 년 이후 $20 \%$ 를 넘을 것으로 예상된다. ${ }^{2)}$ 연령이 증가함에 따라 노인성 질환의 출현율도 함께 증가하고 있으며, 그 중 뇌병변 장애는 65세 이후 급격히 증가하고 있어 인구 1000 명 당 20.84건, 70 대 이후 33.80건, 80 세 이후 22.23 건으로 높은 출현율을 보이고 있다. 노년기의 뇌병변 장애의 주된 진단명을 살펴보면 뇌졸 중 $69.5 \%$, 뇌손상 $11.2 \%$, 뇌성마비 $8.2 \%$ 로 뇌졸중이 가장 많은 비중을 차지 하였다. ${ }^{3)}$ 뇌졸중은 손상 위치와 정도에 따 라 다양한 문제를 나타내는데 주로 운동 및 감각기능 상실, 의사소통 장애, 인지 및 지각 장애, 정서적 변화 등을 초래한

http:dx.doi.org/10.17817/2020.10.10.111583
다. ${ }^{4)}$ 이러한 결과는 역할에 대한 개입을 제한함으로써 개인에 게 만족스러운 삶을 살아가는 것을 방해한다."

역할(Role)이란 본래 연극에서 쓰이던 용어로써 여러 학 자에 의해 서로 다른 방식으로 정의되고 있으나 작업치료 실 행체계(Occupational Therapy Practice Framework; OTPF)에서는 수행패턴의 하위영역으로 '사회에서 기대하는 행동의 집합으로 문화와 배경에서 형태가 만들어지며 대상(사 람, 단체, 인구집단)에 따라 개념이나 정의가 달라질 수도 있 다라고 정의하고 있고, ${ }^{\circ}$ 인간작업모델(Model Of Human Occupation; MOHO)에서는 패턴화(Habituation)의 하위영 역으로 사회적 그리고/또는 개인적으로 정의된 지위와 관련 된 태도 및 행동들을 발현하는 것'이라 정의하며 내면화된 역 할(Internalized role)이라 칭하고 있다. ${ }^{7)}$

역할은 자연 발달 및 생활환경에 따라 지속적으로 변화하 며, ${ }^{8)}$ 사회적 기대에 의해 부여되고 특정 작업으로 개인을 안 내한다. ${ }^{9)}$ 따라서 개인의 활동은 역할에 따라 구성되는데, ${ }^{4)}$ 뇌 
졸중과 같은 질병은 내면화된 역할을 한순간에 박탈하고 제한 할 수 있다. ${ }^{9}$ 수행하는 역할이 상실되면 수행할 수 있는 활동 또한 줄어들게 되는데, 이러한 결과로 자신이 수행하는 활동 역량에 대한 유능감을 느끼는 것을 방해받게 된다. 역량 (Competence)이란 인간작업모델에서 동기(Volition)의 하위 요소인 개인인과(Personal Caution)의 한 부분으로, ${ }^{7}$ 활동역 량은 자신이 수행하는 활동에 대하여 '얼마나 잘 수행하는지' 를 의미한다. 사람은 누구나 자기가 하고 싶어 하는 일을 하 며, 이것을 잘 수행함으로써 자신감을 얻고 내적 동기를 얻게 되는데, ${ }^{7)}$ 즉 자신이 수행하는 활동에 대한 긍정적인 성취감을 통하여 내적 동기를 얻게 된다는 것이다. 이것을 '활동역량 (Activity Competence)'라고 하는데, 뇌졸중 같은 갑작스럽 고 장기적으로 지속되는 장애는 활동과 역할을 변화시키며, ${ }^{10)}$ 정서적인 부분에 문제를 일으켜 자신이 수행하는 활동역량에 대하여 유능감을 느끼는 것을 방해한다.7) 역할수행의 상실은 활동역량 뿐만 아니라 작업참여에도 영향을 미치게 되는데, 작업참여란 내면화 된 역할의 형태로 개인에게 중요한 작업을 수행함으로써 삶의 상황에 참여하는 방식을 뜻한다. $)^{\prime}$

국제 건강, 장애 및 기능 분류(The International Classification of Health, Disability and Function; ICF)에서는 참여를 "개인에 의한 과제 또는 행동의 실행인 활동과는 다른 삶의 상황에의 개입"으로 정의하며, ${ }^{11)}$ 미국 작업치료협회 (AOTA)는 ICF의 참여에 대한 정의를 OTPF에 포함하여 작 업참여를 설명하고 있다. 따라서 작업참여는 건강을 위한 필 수 요소이며 작업참여를 확립하거나 재확립하는 것이 작업치 료의 궁극적 목표이다. ${ }^{12)}$

이처럼 뇌졸중 환자에게 역할수행, 활동역량 그리고 작업 참여가 중요하게 고려되어야 함에도 불구하고 이와 관련된 연 구는 부족한 실정이다. 역할수행에 관한 국내 연구들을 살펴 보면, Yoon ${ }^{13)}$ 의 노인의 사회적 역할수행 및 SOC 대처전략 이 성공적 노화에 미치는 영향에 관한 연구, $\mathrm{Hyun}^{14)}$ 의 장애 아동과 비장애아동의 주 양육자가 인식하는 역할과 삶의 질에 관한 연구 등 역할수행이 건강관련 요소에 영향을 준다 라는 다양한 연구들이 보고되고 있지만 대부분의 연구가 비장애 성 인 및 노인을 대상으로 한 연구가 주류이며, 뇌졸중 노인을 대상으로 한 역할수행, 활동역량과 작업참여에 관한 연구는 부족한 실정이다.

따라서 본 연구는 뇌졸중 노인의 역할수행, 활동역량과 작 업참여의 관련성, 그리고 뇌졸중 노인의 역할수행이 활동역량 과 작업참여에 미치는 영향을 알아봄으로써 뇌졸중 노인의 정 상적인 역할 내면화를 위한 중재의 기반이 되는 기초자료로써 의의를 가지기 위함이다.

\section{II. 연구 방법}

\section{1. 연구대상}

본 연구의 대상은 $\mathrm{S}$ 시에 위치한 $\mathrm{P}$ 병원에 입원 및 외래로 내원 중인 뇌졸중 노인 35 명을 대상으로 하였다. 연구 대상자 의 일반적 특성은 Table 1 과 같으며, 본 연구 대상자의 선정 기준은 만 65 세 이상인 자, 전문의로부터 뇌졸중 진단을 받은 자, 뇌졸중을 제외한 다른 신경학적 질환이 없는 자, 한국형 간이 정신상태검사(MMSE-K) 점수가 24점 이상으로 인지적 문제가 없는 자, 본 연구의 목적을 이해하고 언어적 의사소통 이 가능한 자로 하였다. 모든 연구 대상자들에게 본 연구의 목적과 방법에 대하여 충분한 설명을 하였으며, 연구 참여에 동의를 받은 후 연구를 진행하였다.

\section{2. 연구도구}

1) 역할수행

(1) 역할 체크리스트(Role Checklist Version3; RC V3) 본 연구에서 뇌졸중 노인과 일반 노인의 역할수행을 알아보기 위해 사용되었다. 개인의 일상적인 생활 안에서 작업적인 역 할을 확인하기 위한 평가도구로, Oakley 등기 이 개발한 역할 체크리스트(Role Checklist)를 Scott 등 ${ }^{11)}$ 이 수정한 것이다. 10 가지 역할에 대한 현재 수행 여부를 기재하고, 수행 여부에 따라 만족도 또는 흥미를 기재한다. 본 연구에서는 역할수행 부분만을 사용하였으며, 검사-재검사 신뢰도는 Kappa 값 $0.74 \sim 1.00$ 으로 나타났다. ${ }^{16}$

\section{2) 활동역량}

(1) 작업 질문지(Occupational Questionnaire; $O Q$ )

본 연구에서 뇌졸중 노인과 일반 노인의 활동역량을 평가하기 위해 사용되었으며, $\mathrm{OQ}$ 는 인간작업모델 $(\mathrm{MOHO})$ 에 근거를 둔 평가도구이다. ${ }^{17)}$ Part 1과 Part 2로 구성되는데 Part 1은 대상자의 일과 중 05:00 24:00 동안을 30분 간격으로 각 시 간대마다 주말이나 평일에 가장 중요한 활동들을 기재한다. Part 2는 기재한 활동이 일상생활 활동, 일, 여가활동, 휴식 중 어디에 속하는지 목록화하고, 얼마나 잘하고(perception of competence), 얼마나 중요한지(value), 얼마나 즐기는지 (enjoyment)를 각각 5점 척도에 따라 기록한다. ${ }^{18)}$ 점수가 높 아질수록 활동에 대한 역량, 가치, 즐거움이 낮다는 것을 의미 하며, Smith 등 ${ }^{17)}$ 의 연구에서 하루 시간대별 활동 $68 \%$, 활동 유형 $87 \%$, 활동역량 $77 \%$, 활동가치 $81 \%$, 활동흥미 $77 \%$ 로 신뢰도를 보였다. ${ }^{19)}$ 본 연구에서는 Part 1 과 Part 2 의 '얼마나 잘하는지(perception of competence)' 부분을 사용하였으 며, 30 분 간격으로 기재하였던 목록화 된 활동들의 역량을 총 점으로 제시하였다. 


\begin{tabular}{|c|c|c|c|}
\hline \multicolumn{2}{|c|}{ Classification } & $\mathrm{n}$ & $\%$ \\
\hline \multirow{2}{*}{ Gender } & Male & 22 & 62.9 \\
\hline & Female & 13 & 37.1 \\
\hline \multirow{4}{*}{ Age } & $65 \sim 70$ & 19 & 54.3 \\
\hline & $71 \sim 75$ & 7 & 20.0 \\
\hline & $76 \sim 80$ & 6 & 17.1 \\
\hline & $81 \sim$ & 3 & 8.6 \\
\hline \multirow{3}{*}{ Marital state } & Married & 19 & $54.3)$ \\
\hline & Divorce & 1 & 2.9 \\
\hline & Bereavement & 15 & 42.9 \\
\hline \multirow{5}{*}{ Religion } & Christianity & 12 & 34.3 \\
\hline & Buddhism & 5 & 14.3 \\
\hline & Catholic & 3 & 8.6 \\
\hline & And so on & 1 & 2.9 \\
\hline & Have no religion & 14 & 40.0 \\
\hline \multirow{5}{*}{ Level of education } & Lack of schooling & 8 & 22.9 \\
\hline & Elementary school graduation & 7 & 20.0 \\
\hline & Middle school graduation & 4 & 11.4 \\
\hline & High school graduation & 13 & 37.1 \\
\hline & College graduate & 3 & 8.6 \\
\hline \multirow{2}{*}{ Type of patient } & Hospitalization & 23 & 65.7 \\
\hline & Outgoing & 12 & 34.3 \\
\hline \multirow{3}{*}{ Period of onset } & Under six months & 5 & 14.3 \\
\hline & 6 months to less than 1 year & 7 & 20 \\
\hline & More than a year & 23 & 65.7 \\
\hline \multirow{2}{*}{ Dominant hand } & Right & 25 & 68.6 \\
\hline & Left & 10 & 28.6 \\
\hline \multirow{3}{*}{ Part of paralysis } & Right & 14 & 40.0 \\
\hline & Left & 20 & 57.1 \\
\hline & Both & 1 & 2.9 \\
\hline
\end{tabular}

3) 작업참여

(1) 인간작업모델 선별 평가(Model Of Human Occupation Screening Tool; MOHOST)

본 연구에서 뇌졸중 노인과 일반 노인의 작업참여를 평가하기 위해 사용하였으며, 작업의지, 패턴화, 의사소통 상호관계기술, 처리기술, 운동기술, 환경 등의 하위영역으로 이루어져 있다. 각 하위 영역은 다시 4 개 항목으로 총 24 개의 문항으로 구성 되며, 각 문항은 4점 척도로 최저 24점에서 최고 96점으로 점수가 높을수록 작업참여가 높다는 것을 의미한다. 면담 또는
관찰 등의 여러 가지 방법으로 평가할 수 있다. Kielhofner 등 $^{20)}$ 의 연구에서 .81 .89의 신뢰도를 보였다.

\section{3. 연구절차}

본 연구는 2018년 9월 20일부터 2018년 10월 20일까지 이 루어졌으며, $\mathrm{S}$ 시에 위치한 $\mathrm{P}$ 병원에 입원 및 외래로 내원 중인 뇌졸중 노인 35명을 대상으로 역할 체크리스트(RC V3), 작업 질문지 $(\mathrm{OQ})$ 와 인간작업모델 선별 평가(MOHOST)를 사용하 여 평가를 진행하였다. 모든 평가는 본 연구자가 직접 일대일 
면담을 통해 진행하였고, 개인당 약 30 분정도의 시간이 소요 되었으며, 시끄럽지 않고 환자가 느끼기에 편안한 장소에서 시행되었다.

\section{4. 분석방법}

수집된 자료는 SPSS Window 22.0 프로그램을 사용하여 통 계 분석하였으며, 분석 방법은 다음과 같다. 연구 대상자의 일 반적 특성을 알아보기 위해 빈도분석을 실시하였으며, 역할수 행, 활동역량과 작업참여 간 상관관계를 알아보기 위해 피어 슨 상관분석을 실시하였다. 역할수행이 활동역량과 작업참여 에 미치는 인과관계를 알아보기 위해 단순회귀분석을 실시하 였으며, 일반적 특성에 따른 역할수행, 활동역량, 작업참여를 알아보기 위해 독립표본 $\mathrm{t}$-검정과 일원산분산분석를 실시하였 다. 분석 결과에 대한 통계학적 유의수준은 .05로 설정하였다.

\section{III. 결 과}

\section{1. 뇌졸중 노인의 역할수행, 활동역량과 작업참여 간 상관관계}

Table 2는 뇌졸중 노인의 역할수행, 활동역량과 작업참여 간 상관분석 결과를 나타낸다. 뇌졸중 노인의 역할수행, 활동역량 과 작업참여 간 상관관계를 알아본 결과, 뇌졸중 노인의 역할 수행은 활동역량 $(\mathrm{r}=.395, \mathrm{p}<.05)$ 과 작업참여 $(\mathrm{r}=.556, \mathrm{p}<.05)$ 에 통계학적으로 유의한 상관관계를 나타냈다.

\section{2. 뇌졸중 노인의 역할수행이 활동역량에 미치는 영향}

뇌졸중 노인의 역할수행이 활동역량에 미치는 영향에 대하여 $\Delta R^{2}=130$ 으로 통계학적으로 유의한 차이를 나타냈다 $(\mathrm{p}<.05)($ Table 3).

결과에 따른 추정된 회귀식은 다음과 같다. $\hat{Y}=.3741+$ $.142 *$ 역할수행.

\section{3. 뇌졸중 노인의 역할수행이 작업참여에 미치는 영향}

뇌졸중 노인의 역할수행이 작업참여에 미치는 영향에 대하여 $\Delta R^{2}=.288$ 으로 통계학적으로 유의한 차이를 나타냈다 $(\mathrm{p}<.01)$ (Table 4).

결과에 따른 추정된 회귀식은 다음과 같다. $\hat{Y}=70.743+$ $2.890 *$ 역할수행

Table 2. The relationship between role Performance, activity competence, and occupational participation of the elderly with stroke

\begin{tabular}{cccc} 
& Role Performance & Activity Competence $^{+}$ & Occupational Participation $^{\text {Role Performance }}$ \\
Activity Competence & 1 & & \\
Occupational Participation & $.395^{*}$ & 1 & 1 \\
\hline
\end{tabular}

+Reverse coding

${ }^{*} p<.05$

Table 3. The effect of role performance of the elderly with stroke on activity competence and occupational participation

\begin{tabular}{|c|c|c|c|c|}
\hline \multirow{2}{*}{ Predictor } & \multicolumn{3}{|c|}{ Activity Competence $^{+}$} & \multirow{2}{*}{$\mathrm{t}$} \\
\hline & B & SE & $\beta$ & \\
\hline (Constant) & .3741 & 177 & & \\
\hline Role Performance & .142 & .057 & .395 & $2.468^{\prime \prime}$ \\
\hline$\Delta R^{2}$ & .130 & & & \\
\hline
\end{tabular}

+Reverse coding

${ }^{*} \mathrm{p}<.05$

Table 4. The effect of role performance of the elderly with stroke on activity competence and occupational participation

\begin{tabular}{ccccc}
\hline \multirow{2}{*}{ Predictor } & \multicolumn{3}{c}{ Occupational Participation } & $\mathrm{t}$ \\
\cline { 2 - 3 } (Constant) & $\mathrm{B}$ & $\mathrm{SE}$ & & \\
Role Performance & 70.743 & 2.319 & .556 & $3.845^{*}$ \\
$\Delta R^{2}$ & 2.890 & .752 & & \\
\hline
\end{tabular}

${ }^{*} p<.01$ 


\section{4. 일반적 특성에 따른 뇌졸중 노인의 역할수행, 활동역량과 작업참여}

Table 5는 일반적 특성에 따른 뇌졸중 노인의 역할수행, 활동 역량과 작업참여의 차이를 나타낸다. 그 중 종교에 따른 역할 수행이 통계학적 유의한 차이를 나타냈으며( $\mathrm{p}<.05)$, 내원형태 에 따른 역할수행 $(\mathrm{p}<.01)$, 활동역량 $(\mathrm{p}<.001)$ 과 작업참여 ( $\mathrm{p}<.001)$ 모두 통계학적으로 유의한 차이를 나타냈다.

또한 뇌졸중 노인의 환측에 따른 작업참여도 통계학적으로
유의한 차이를 나타냈다 $(\mathrm{p}<.05)$.

\section{IV. 고 찰}

본 연구는 뇌졸중 노인의 역할수행, 활동역량과 작업참여의 관련성과 뇌졸중 노인의 역할수행이 활동역량과 작업참여에 미치는 영향을 알아보고자 하였다.

Table 5. Difference in role performance, activity competence and occupational participation of the elderly with stroke according to general characteristics

\begin{tabular}{|c|c|c|c|c|c|c|c|}
\hline & & \multicolumn{2}{|c|}{ Role Performance } & \multicolumn{2}{|c|}{ Activity Competence } & \multicolumn{2}{|c|}{$\begin{array}{l}\text { Occupational } \\
\text { Participation }\end{array}$} \\
\hline & & $\mathrm{M} \pm \mathrm{SD}$ & $t / F$ & $M \pm S D$ & $t / F$ & $\mathrm{M} \pm \mathrm{SD}$ & $t / F$ \\
\hline \multirow{2}{*}{ Gender } & Male & $2.45 \pm 1.56$ & \multirow{2}{*}{-.659} & $4.09 \pm .52$ & \multirow{2}{*}{-.167} & $78.59 \pm 9.06$ & \multirow{2}{*}{.290} \\
\hline & Female & $2.85 \pm 1.90$ & & $4.13 \pm .74$ & & $77.69 \pm 8.51$ & \\
\hline \multirow{4}{*}{ Age } & $65 \sim 70$ & $2.84 \pm 2.08$ & \multirow{4}{*}{.334} & $4.17 \pm 0.54$ & & $78.74 \pm 10.67$ & \multirow{4}{*}{.285} \\
\hline & $71 \sim 75$ & $2.14 \pm 1.06$ & & $3.60 \pm 0.59$ & & $75.57 \pm 6.16$ & \\
\hline & $76 \sim 80$ & $2.33 \pm 1.21$ & & $4.42 \pm 0.42$ & 2.658 & $79.83 \pm 7.11$ & \\
\hline & $81 \sim$ & $2.67 \pm 0.57$ & & $4.24 \pm 0.89$ & & $78.33 \pm 1.15$ & \\
\hline \multirow{3}{*}{ Marital state } & Married & $3.11 \pm 1.99$ & \multirow{3}{*}{1.979} & $4.21 \pm 0.57$ & & $78.47 \pm 11.06$ & \multirow{3}{*}{.019} \\
\hline & Divorce & $2.00 \pm 0.00$ & & $4.05 \pm 0.00$ & .645 & $79.00 \pm 0.00$ & \\
\hline & Bereavement & $2.00 \pm 1.00$ & & $3.97 \pm 0.65$ & & $77.93 \pm 5.31$ & \\
\hline \multirow{5}{*}{ Religion } & Christianity & $3.75 \pm 2.00$ & \multirow{5}{*}{$2.811^{*}$} & $4.07 \pm 0.68$ & & $81.17 \pm 7.63$ & \multirow{5}{*}{2.567} \\
\hline & Buddhism & $1.60 \pm 1.14$ & & $4.40 \pm 0.33$ & & $68.60 \pm 12.70$ & \\
\hline & Catholic & $2.33 \pm 2.51$ & & $3.82 \pm 0.90$ & .497 & $74.67 \pm 8.50$ & \\
\hline & And so on & $3.00 \pm 0.00$ & & $3.81 \pm 0.00$ & & $84.00 \pm 0.00$ & \\
\hline & Have no religion & $2.00 \pm 0.78$ & & $4.12 \pm 0.57$ & & $79.57 \pm 6.24$ & \\
\hline \multirow{5}{*}{ Level of education } & Lack of schooling & $1.63 \pm 1.30$ & \multirow{5}{*}{1.040} & $3.80 \pm 0.71$ & & $75.50 \pm 3.29$ & \multirow{5}{*}{.873} \\
\hline & Elementary school graduation & $2.71 \pm 1.11$ & & $4.07 \pm 0.73$ & & $77.86 \pm 4.74$ & \\
\hline & Middle school graduation & $3.50 \pm 2.38$ & & $4.11 \pm 0.75$ & 1.407 & $75.50 \pm 15.54$ & \\
\hline & High school graduation & $2.85 \pm 1.90$ & & $4.17 \pm 0.39$ & & $79.31 \pm 10.78$ & \\
\hline & College graduate & $2.67 \pm 1.52$ & & $4.72 \pm 0.10$ & & $85.67 \pm 0.57$ & \\
\hline \multirow{2}{*}{ Type of patient } & Hospitalization & $1.96 \pm 0.97$ & \multirow{2}{*}{$-2.958^{* *}$} & $3.84 \pm 0.58$ & $5780^{\text {sten }}$ & $74.43 \pm 8.07$ & \multirow{2}{*}{$-4.465^{* *}$} \\
\hline & Outgoing & $3.83 \pm 2.08$ & & $4.61 \pm 0.18$ & -5.780 & $85.58 \pm 4.12$ & \\
\hline \multirow{3}{*}{ Period of onset } & Under six months & $2.40 \pm 1.14$ & \multirow{3}{*}{2.602} & $3.70 \pm 0.74$ & & $76.40 \pm 7.23$ & \multirow{3}{*}{.467} \\
\hline & 6 months to less than 1 year & $1.43 \pm 0.97$ & & $4.03 \pm 0.68$ & 1.638 & $76.14 \pm 9.77$ & \\
\hline & More than a year & $3.00 \pm 1.80$ & & $4.21 \pm 0.53$ & & $79.30 \pm 8.91$ & \\
\hline \multirow{2}{*}{ Dominant hand } & Right & $2.24 \pm 1.23$ & \multirow{2}{*}{-1.627} & $4.09 \pm 0.58$ & 218 & $76.68 \pm 8.82$ & \multirow{2}{*}{-1.735} \\
\hline & Left & $3.50 \pm 2.32$ & & $4.14 \pm 0.67$ & -.218 & $82.20 \pm 7.58$ & \\
\hline \multirow{3}{*}{ Part of paralysis } & Right & $3.14 \pm 2.10$ & \multirow{3}{*}{1.240} & $4.19 \pm 0.60$ & & $80.00 \pm 9.51$ & \\
\hline & Left & $2.25 \pm 1.29$ & & $4.05 \pm 0.62$ & .238 & $78.05 \pm 7.14$ & $3.378^{*}$ \\
\hline & Both & $2.00 \pm 0.00$ & & $4.05 \pm 0.00$ & & $58.00 \pm 0.00$ & \\
\hline
\end{tabular}

${ }^{*} p<.05,{ }^{* *} p<.01,{ }^{* * *} p<.001$ 
뇌졸중 노인의 역할수행과 활동역량의 상관관계에 대하여 알아본 결과, 역할수행과 활동역량은 통계학적으로 유의한 상 관관계를 나타냈다(r=.395, p<.05). 따라서 뇌졸중 노인이 현 재 수행하는 역할이 많아질수록 일상에서 수행하는 전반적인 활동들을 잘 수행한다는 것을 의미하는데, Meidert 등 ${ }^{21}$ 은 학 생, 직장인, 자원봉자사 등 10 가지 역할을 국제 기능, 장애, 건강 분류(ICF)의 항목과 링킹을 하였다. 그 결과 10 가지의 각 역할들이 $\mathrm{ICF}$ 의 활동과 참여의 여러 항목과 연결이 되었 으며, 이것은 역할이 다양한 활동들을 구성하고 있다는 것을 입증하는 결과이다. 그러므로 본 연구의 결과와 함께 종합해 보면, 많은 역할을 수행하는 것은 그만큼 다양한 활동들을 많 이 수행하게 되고, 일상에서 수행하는 활동들에 대한 수행도 가 높아진다는 것을 의미하게 된다.

뇌졸중 노인의 역할수행과 작업참여의 상관관계에 대하여 알아본 결과, 역할수행과 작업참여는 유의한 상관관계를 나타 냈다 $(\mathrm{r}=.556, \mathrm{p}<.05)$. 따라서 수행하는 역할이 많아질수록 작 업참여가 높다는 것을 의미한다. Scott 등 ${ }^{22)}$ 은 간 이식 수술 을 받은 환자의 역할수행과 작업참여의 상관성에 대하여 연구 하였는데, 역할수행이 많아질수록 작업참여가 높아진다는 연 구 결과를 제시하였고, 본 연구와 비교해서 대상자는 달랐지 만 그 결과는 유사하였다.

뇌졸중 노인의 역할수행이 활동역량에 미치는 영향에 대하 여 알아본 결과, 통계학적으로 유의한 영향을 나타냈다 $\Delta R^{2}$ $=.130, \mathrm{p}<.05)$. 그러나 $\Delta R^{2}$ 값이 크게 나타나지 않았는데, 이것은 각 개인마다 노출된 환경적.배경적 요소의 영향 때문 인 것으로 사료된다. Mckenna 등ํㅡㄴ 환경적 장벽이 지역사 회 기반 역할에 참여하는 능력에 영향을 줄 수 있다고 하였으 며, $\operatorname{Reid}^{23)}$ 는 뇌졸중 노인에게 계단과 같은 환경에 대한 접근 성의 어려움이 역할수행의 주요 장벽이라고 하였다. 이러한 근거들을 종합해볼 때 각각의 다른 환경과 배경이 개인의 역 할에 영향을 주는 요인으로써 작용하는 것으로 사료되며, 따 라서 추가적인 연구를 통하여 역할에 영항을 주는 환경과 배 경요소들을 요인분석을 통해 파악한 뒤, 결과에 따라 나타난 요인들을 통제하여 역할기반 실험연구를 통해 역할수행이 활동 역량에 미치는 영향에 대한 추가적인 연구를 제안하는 바이다.

뇌졸중 노인의 역할수행이 작업참여에 미치는 영향에 대하여 알아본 결과, 통계학적으로 유의한 영향을 나타냈다 $\left(\Delta R^{2}=.288\right.$, $\mathrm{p}<.01)$. 따라서 역할을 수행하면 작업참여에 변화를 준다는 것을 의미하는데, Bonsaksen 등 ${ }^{12)}$ 은 작업참여를 확립하거나 재확립하는 것이 작업치료의 궁극적 목표라고 하였고, $\mathrm{Scott}^{16)}$ 은 “하나의 역할에 참여하는 것이 작업참여이다" 라고 주장하 였다. 선행연구와 본 연구의 결과를 종합해볼 때 역할수행이 작업참여에 영향을 주었기 때문에 역할수행을 촉진하는 것을 통하여 작업치료의 궁극적인 목표인 작업참여를 이룰 수 있을
것으로 사료된다. 따라서 역할수행을 촉진시키는 다양한 중재 방법들에 대한 개발 및 연구를 제안하는 바이다.

뇌졸중 노인의 일반적 특성에 따른 역할수행, 활동역량과 작업참여의 차이를 알아본 결과, 종교에 따른 역할수행이 통 계학적으로 유의한 차이를 나타냈는데 $(\mathrm{p}<.05)$, 이것은 역할체 크리스트(RC V3) 평가도구의 특성상 역할수행 항목에 종교인 역할이 포함되어 있다. 따라서 종교를 가진 뇌졸중 노인에게 평가도구가 민감하게 반응하여 나타났던 결과로 판단된다.

뇌졸중 노인의 내원형태에 따라 역할수행( $\mathrm{p}<.01)$, 활동역 량 $(\mathrm{p}<.001)$ 과 작업참여 $(\mathrm{p}<.001)$ 에서 통계학적으로 유의한 차 이를 나타냈다. 이것은 환경적인 요인과 내원형태에 따른 뇌 졸중 노인의 신체적 인지적 기능의 차이 때문에 나타난 결과 로 볼 수 있다. 역할은 사회적 기대에 따라 부여가 되는 특성 이 있지만,9) 입원 환자의 경우 병원이라는 환경이 사회와 떨 어져 있기 때문에 사회적 기대에 의한 역할수행 부여가 제한 이 되었던 것으로 사료된다.

뇌졸중 노인의 환측에 따른 작업참여의 차이에서 통계학적 으로 유의한 차이를 나타냈다 $(\mathrm{p}<.05)$. 우측 편마비와 좌측 편 마비에서 점수의 차이를 나타냈는데, 우측 편마비는 $80.00 \pm 9.51$, 좌측 편마비는 $78.05 \pm 7.14$ 를 나타냈다. 평균과 표준편차 점수의 차이만을 보면 우측 편마비가 좌측 편마비보 다 작업참여 점수가 약간 높게 나타난 것을 볼 수 있다. 연구 결과에는 제시하지 않았지만 양측 마비를 제외한 뒤, 우측 편 마비와 좌측 편마비의 작업참여 차이에 대한 통계적 유의성을 확인하였다. 그 결과 두 집단간 유의한 차이를 나타내지 않았 다(p>.05). Park 등 ${ }^{24}$ 은 뇌졸중 환자의 우세손 마비 유무에 따른 기능 회복의 변화량 차이를 분석하였고, 우세손 마비 유 무에 따른 일상생활활동에서는 차이가 없다 라는 결과를 제시 하였다. 따라서 본 연구의 결과와 대체로 비슷한 결과가 나타 난 것을 알 수 있었다.

뇌졸중 노인의 발병기간에 따른 역할수행은 통계학적으로 유의한 차이를 나타내지 않았는데( $\mathrm{p}>.05)$, 뇌졸중 발병 후 시 간이 지나도 역할 수행에 있어 차이가 없다는 것을 의미한다. 선행연구에서 하나의 역할은 다양한 활동과 작업들로 구성되 었다고 하였으며, 역할체크리스트(RC V3)의 10 가지 역할들은 식사준비하기, 집안일 하기, 낮선 사람과 관계 맺기, 가족관계, 교육, 유급고용 등 일상생활활동과 거리가 먼 활동들로 링킹 이 되었다. ${ }^{21)}$ 국내 의료기사법에 명시되어 있는 작업치료사의 업무의 범위 중 하나는 일상생활활동 훈련이 있으며, 실제 임 상에서 대부분의 작업치료사들이 일상생활활동 훈련을 시행하 고 있으나 역할수행에 초점을 둔 치료와 연구에 대한 관심이 부족한 실정이다. 앞서 언급했듯이 10 가지의 역할은 일상생활 활동과 거리가 먼 활동들이라 하였다. 따라서 일상생활활동 등의 기타 치료들뿐만 아니라 역할수행에 초점을 둔 치료를 
병행한다면 발병 기간에 따라 역할수행의 점수에 차이가 나타 날 것이라 사료된다.

뇌졸중 노인의 발병기간에 따른 활동역량은 통계학적으로 유의한 차이를 나타내지 않았는데(p>.05), 뇌졸중 발병한 뒤 시간이 지나도 일상에서 수행하는 활동에서 느끼는 역량감이 차이가 없다는 것을 뜻한다. 많은 연구들에서 뇌졸중 노인들 이 병원에 입원 및 내원하여 재활 치료를 받고 건강관련 기능 이 향상되었다고 보고하고 있다. 이러한 결과를 표면적으로만 보았을 때 본 연구의 결과가 모순되었다고 판단할 수 있다. 하지만 개인이 주관적으로 느끼는 심리적 측면에서는 차이가 나타나지 않았을 수도 있다. 왜나하면 뇌졸중이 발병하지 않 았을 때만큼의 건강기능 회복이 이루어지지 않았기 때문에 발 병기간이 지나도 뇌졸중 노인들이 일상생활에서 느끼는 활동역 량에 대한 변화가 나타나지 않았을 것이라 사료되기 때문이다.

뇌졸중 노인의 발병 기간에 따른 작업참여는 통계학적으로 유의한 차이를 나타내지 않았는데(P>.05), 뇌졸중이 발병한 뒤 시간이 지나도 전반적인 작업참여에 차이가 없다는 것을 뜻한다. 6개월 미만 발병 기간에 따른 작업참여는

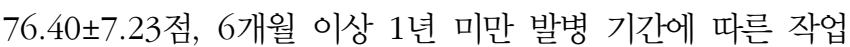
참여는 $76.14 \pm 9.77$ 점, 1 년 이상의 발병 기간에 따른 작업 참 여는 79.30 \pm 8.91 점으로 발병 기간 6개월 미만과 6개월 이상 1 년 미만의 작업참여 점수는 크게 차이가 나지 않았으나 1 년 이상에서부터 작업참여의 점수의 차이가 나타났다. 이러한 결과 는 노화와 질병이 겹쳐 발생한 결과라 사료되는데, 평소에 재활 치료를 받아도 노화 때문에 회복이 더딜 수 있기 때문이다.

본 연구에서는 활동역량을 각 활동에 대한 점수를 제시하 지 않고 총점으로 제시하여 통계분석 하였다. 이는 작업설문 지(OQ)를 통해 하루에 수행하는 활동들을 목록화하고, 목록 화 된 활동들을 4 가지의 카테고리에 각각 포함시킬 때 개인이 정의하는 작업이 다르기 때문에 개인마다 차이를 나타낼 것으 로 추측되어 연구 결과에 영향을 미칠 것이라 판단하였다. 따 라서 본 연구 목적의 취지에 맞게 활동역량 전체 점수를 사용 하여 연구를 진행하였다.

본 연구의 제한점으로는 대상자 수가 적어 연구를 일반화 하는데 어려우며, 역할수행은 환경에 영향을 받기 때문에 환 경적인 요소를 고려한 추가적인 연구가 필요할 것으로 사료된 다. 또한 작업 질문지(OQ)를 통해 하루 중 5:00 24:00에 활 동하는 전반적인 활동역량에 대하여 파악한 것에 의의를 가지 나, 일상에서 수행하는 모든 활동들을 세분화여 파악하지 못 하였다.

본 연구는 뇌졸중 노인의 역할수행, 활동역량과 작업참여 의 관련성, 그리고 뇌졸중 노인의 역할수행이 활동역량과 작 업참여에 미치는 영향을 알아보고자 하였다. 그 결과 뇌졸중 노인의 역할수행은 활동역량, 작업참여와 상관관계를 나타냈
으며, 뇌졸중 노인의 역할수행이 활동역량과 작업참여에 영향 을 미치는 것으로 나타났다. 따라서 뇌졸중 노인에게 역할 내 면화를 위한 역할수행 촉진과 중재에 관심을 가진다면, 뇌졸 중 노인의 활동역량과 작업참여를 향상시킬 수 있을 것이라 판단된다. 또한 더 많은 대상자수를 모집하고, 환경적 요소를 고려한 뒤, 다양한 질환에 따른 역할수행과 건강관련 요소들 에 대한 추가적인 연구를 진행한다면 다양한 관점에서 역할 내면화에 대한 연구 결과를 제시할 수 있고, 이를 통해 작업 치료 발전에 도움이 될 수 있을 것이라 사료된다.

\section{References}

1. Kim CD. Study of influence of role loss in the elderly on suicide thinking : focused on verification of the mediating effect of depressive symptoms. Baekseok University. Dissertation of Doctorate Degree. 2014.

2. Statistics Korea. Future Population Special Estimation: 2017-67.

3. Ministry of Health and Welfare. Survey on the Actual Conditions of the Disabled. 2014.

4. McKenna K, Liddle J, Brown A, et al. Comparison of time use, role participation and life satisfaction of older people after stroke with a sample without stroke. Australian Occupational Therapy Journal. 2009;56(3) :177-88.

5. Clarke P, Marshall V, Black SE, et al. Well-being after stroke in Canadian seniors: findings from the Canadian Study of Health and Aging. Stroke. 2002;33(4):1016-21.

6. American Occupational Therapy Association. Occupational Therapy Practice Framework: Domain and process, 3rd edition. American Journal of Occupational Therapy. 2017.

7. Kielhofner G. A Model of Human Occupation: Theory and application (4th ed.). Baltimore, MD: Lippincott Williams \& Wilkins. 2008

8. Scott PJ, McFadden R, Yates K, et al. The Role Checklist V2: QP: Establishment of reliability and validation of electronic administration. British Journal of Occupational Therapy. 2014;77(2):96-102.

9. Bonsaksen $\mathrm{T}$, Kvarsnes $\mathrm{H}$. Role performance and role valuation among occupational therapy students in Norway. The Open Journal of Occupational Therapy. 2016;4(1):7.

10. Morgan D, Jongbloed L. Factors influencing leisure 
activities following a stroke: An exploratory study. Canadian Journal of Occupational Therapy. 1990;57(4): 223-9.

11. Scott PJ, McKinney K, Perron J, et al. Measurement of participation: The Role Checklist Version 3: Satisfaction and performance. Occupational therapy: Occupation focused holistic practice in rehabilitation. 2017;107-19.

12. Bonsaksen T, Meidert U, Schuman D et al. Does the Role Checklist measure occupational participation?. The open journal of occupational therapy. 2015;3(3).

13. Yoon KO. A Study on the Effect of Social Role Performance and SOC Coping Strategies of the Successful Aging: A Comparison between the Employed and the Unemployed Seniors. Catholic University. Dissertation of Master's Degree. 2012.

14. Hyun JY. Role Identification and Quality of Life Perceived by Main Fosterers of Children with and without disabilities; Focusing on Jeju Special Self-Governing Province. Daegu University. Dissertation of Master's Degree. 2014.

15. Oakley F, Kielhofner G, Barris R, et al. The Role Checklist: Development and empirical assessment of reliability. The Occupational Therapy Journal of Research. 1986;6(3):157-70.

16. Scott PJ, McKinney KG, Perron JM, et al. The Revised Role Checklist: Improved Utility, Feasibility, and Reliability. OTJR (Thorofare N J). 2019;39(1):56-63.

17. Smith NR, Kielhofner G, Watts JH. The relationships between volition, activity pattern, and life satisfaction in the elderly. American Journal of Occupational Therapy. 1986;40(4):278-83.

18. Sim HR. Effects of Time-Use Intervention on SelfEfficacy and the Six Factors Influencing Occupational Participation for Stroke Survivor. Daegu University. Dissertation of Master's Degree. 2017.

19. Henry AD, Costa C, Ladd D et al. Time use, time management and academic achievement among occupational therapy students. Work. 1996;6(2):115-26.

20. Kielhofner G, Fan CW, Morley M, et al. A psychometric study of the Model of Human Occupation Screening Tool (MOHOST). Hong Kong Journal of Occupational Therapy. 2010;20(2):63-70.

21. Meidert U, Bonsaksen T, Scott PJ. A study of measuring participation according to the International Classification of Functioning, Disability and Health with the Revised Role Checklist. Clinical rehabilitation. 2018;32(11): 1530-9.

22. Scott PJ, Cacich D, Fulk M, et al. Establishing concurrent validity of the Role Checklist version 2 with the OCAIRS in measurement of participation: a pilot study. Occupational therapy international. 2017.

23. Reid D. Impact of the environment on role performance in older stroke survivors living at home. International journal of therapy and rehabilitation. 2004;11(12):567-73.

24. Park JM, Kim HD, Hwang DY et al. Retrospective Cohort Survey on Post Stroke Recovery in Accordance With Hand Dominance. The Journal of Korean Society of Occupational Therapy. 2018;26(1):1-13. 